\title{
Malaria or COVID-19? A case report highlighting a diagnostic challenge in Africa
}

Menelas Nkeshimana ( $\nabla$ mnls.nke@gmail.com )

Centre Hospitalier Universitaire de Kigali https://orcid.org/0000-0003-3573-8075

\section{Sabin Nsanzimana}

Rwanda Biomedical Centre https://orcid.org/0000-0002-5946-0015

\section{Case Report}

Keywords: Malaria, COVID-19, Communicable Diseases, Coinfection, Tropical Medicine, Africa

Posted Date: January 13th, 2021

DOI: https://doi.org/10.21203/rs.3.rs-144340/v1

License: (c) (i) This work is licensed under a Creative Commons Attribution 4.0 International License. Read Full License 


\section{Abstract}

A 40 years old woman previously healthy was diagnosed and treated for malaria without any significant improvement. At the concern of an increase in shortness of breath, she consulted the nearby hospital where an additional diagnosis of COVID-19 infection was made. She died shortly after due to severe COVID-19 Pneumonia. In countries like Rwanda where $70 \%$ of malaria cases are treated at community level by community health workers, typical malaria signs and symptoms (fever, shivering, headache, fatigue, muscle aches, diarrhea, vomiting) are well known by lay providers and even by patients themselves. These overlap with common COVID-19 symptoms. It is very likely that unrecognized COVID19 disease transmitters will lead to a much wider virus spread, especially by those patients for whom a concurrent malarial disease is easily confirmed using the widely available malaria rapid tests. There is a growing need to reinforce the ability of fragile health systems to discriminate between multiple common causes for common symptoms, especially for malaria and COVID-19 infection.

\section{Case Presentation}

A 40 years old woman previously healthy, living in a suburban neighborhood in Rwanda presented with general malaise and fever. She reported to the nearby clinic in her community where a diagnosis of malaria was made. She was provided with a 3-days course of oral antimalarial drugs (artemetherlumefantrine), which she completed without any significant improvement. At the concern of an increasing shortness of breath, she decided to go for further medical consultation at the hospital whereby a rapid test for COVID-19 was done and it was reported positive. Within a short time, her respiratory function deteriorated with a rate of 57 breaths per minute and her oxygen saturation was fluctuating around $60 \%$ on oxygen supplementation of 15 liters per minute. Her chest X-ray was significant for bilateral diffuse lungs opacifications. Additional blood work-up was done, including the complete blood count, malaria smear and metabolic panel [see table 1 below]. She was started on drugs therapy including dexamethasone, heparin and broad spectrum antibiotherapy without any significant improvement. As per the COVID-19 management guidelines, she met the criteria for endotracheal intubation and a referral to the designated COVID-19 Treatment Center where she died one day after arrival. This case report highlights the need to review the diagnostic approach for COVID-19 in this wetter season known with an increase in incidence of malarial disease.

Table 1: Laboratory parameters of the patient presented above 


\begin{tabular}{|llll|}
\hline Parameter & Unit of measure & Result & Reference range \\
\hline White Cell Count & $\mathrm{x} 10^{9} / \mathrm{L}$ & 5.4 & $4.5-11.5$ \\
\hline Neutrophils & $\mathrm{x} 10^{9} / \mathrm{L}$ & 4.23 & $1.1-4.4$ \\
\hline Lymphocytes & $\mathrm{x} 10^{9} / \mathrm{L}$ & 0.67 & $1.3-3.7$ \\
\hline Monocytes & $\mathrm{x} 10^{9} / \mathrm{L}$ & 0.49 & $0.12-0.6$ \\
\hline Hemoglobin & $\mathrm{g} / \mathrm{dL}$ & 13.4 & $11-17$ \\
\hline Platelets & $\mathrm{x} 10^{9} / \mathrm{L}$ & 257 & $150-450$ \\
\hline Erythrocyte Sedimentation Rate & $\mathrm{mm} / \mathrm{h}$ & 18 & $1-20$ \\
\hline C-reactive protein & $\mathrm{mg} / \mathrm{L}$ & 332 & $0-5$ \\
\hline Sodium (serum) & $\mathrm{mmol} / \mathrm{L}$ & 133 & $136-145$ \\
\hline Potassium (serum) & $\mathrm{mmol} / \mathrm{L}$ & 5.7 & $3.5-5.1$ \\
\hline Chloride (serum) & $\mathrm{mmol} / \mathrm{L}$ & 92.3 & $98-107$ \\
\hline Urea & $\mathrm{mmol} / \mathrm{L}$ & 7.0 & $1-7.5$ \\
\hline Creatinine & $\mathrm{micromol} / \mathrm{L}$ & 77 & $44-80$ \\
\hline Alanine aminotransferase & $\mathrm{IU} / \mathrm{L}$ & 45.2 & $5-40$ \\
\hline Asparate aminotransferase & $\mathrm{IU} / \mathrm{L}$ & 86.3 & $5-40$ \\
\hline Gamma-glutamyl transferase & $\mathrm{IU} / \mathrm{L}$ & 116 & $5-60$ \\
\hline Glucose, random (serum) & $\mathrm{mmol} / \mathrm{L}$ & 16.36 & $4.1-6.72$ \\
\hline Malaria smear & $\mathrm{N} / \mathrm{A}$ & $\mathrm{negative}$ & $\mathrm{negative}$ \\
\hline
\end{tabular}

\section{Literature Review}

When COVID-19 was first reported, epidemiologists predicted unprecedented increase of deaths in countries with weak health systems that were already struggling to manage a large number of infectious diseases (Ellie SS 2020). Sub-Saharan Africa (SSA) accounts for nearly half (49\%) of infectious diseases burden worldwide, with HIV, tuberculosis and malaria responsible for much of the mortality and morbidity caused by infectious diseases (C.M Michaud 2009, Snow RW \& Omumbo JA 2006). As the total number of COVID-19 patients continue to increase worldwide, the African continent is seemingly less affected yet surpassing two millions of total confirmed cases and 59,746 COVID-19 related deaths (Africa CDC 2020).

Reverse Transcriptase Polymerase Chain Reaction (RT-PCR) has become a backbone of testing SARS COV-2 globally. Laboratories in Africa face serious challenges of limited diagnostics infrastructure, great 
variety of testing protocols needing local validation, high cost of PCR tests, limited supply chain and analysis rendering difficult all possibilities of early diagnosis and isolation of contacts (Waidi Folorunso Sule et al. 2020, Kobia F. et al. 2020). As of December $1^{\text {st }} 2020$, Rwanda had done a total 629,131 RT-PCR tests for COVID-19 since the pandemic begun, and several rapid diagnostic kits are under assessment and validation process. Reliable COVID-19 testing is critical for countries in Sub-Saharan Africa that face a high burden of malaria, and clinicians are challenged to differentiate malaria signs and symptoms from those caused by COVID-19 infection. Malaria is a leading cause of childhood deaths in sub-Saharan Africa, with an incidence of 229 cases per 1000 population at risk, and 380,000 malaria deaths mainly among children under 5 reported in 2018 (WHO 2019).

In countries like Rwanda where $70 \%$ of malaria cases are treated at community level by community health workers - an approach that has helped to reduce malaria related deaths from 715 in 2016 to 314 in 2018 (Malaria Operational Plan FY 2020) - typical malaria signs and symptoms (fever, shivering, headache, fatigue, muscle aches, diarrhea, vomiting) are well known by lay providers and even by patients themselves. These overlap with common COVID-19 symptoms [see table 2 below].

Table 2: Comparison of signs and symptoms of Malaria versus COVID-19

\begin{tabular}{|lll|}
\hline $\begin{array}{l}\text { Relatively unique } \\
\text { for Malaria }\end{array}$ & Common Signs and Symptoms & Relatively unique for COVID-19 \\
\hline $\begin{array}{l}\text { Nausea, vomiting, } \\
\text { dizziness, pale } \\
\text { conjunctiva, } \\
\text { jaundice, dark } \\
\text { urine, confusion, } \\
\text { seizures and } \\
\text { coma. }\end{array}$ & $\begin{array}{l}\text { Fever, chills, headache, muscles } \\
\text { pain and fatigue. }\end{array}$ & $\begin{array}{l}\text { Cough, sore throat, running nose, nasal } \\
\text { congestion, new loss of smell and taste, } \\
\text { chest pain and difficulty in breathing (due } \\
\text { to ARDS). Sudden death from silent } \\
\text { hypoxia and cardiac injury has also been } \\
\text { cited. }\end{array}$ \\
& $\begin{array}{l}\text { 1. Complicated forms of } \\
\text { Plasmodium falciparum } \\
\text { infection can result in severe } \\
\text { difficulty in breathing (due to } \\
\text { ARDS, or severe anemia causing } \\
\text { heart failure). }\end{array}$ & \\
& $\begin{array}{l}\text { 2. Abdominal pain and } \\
\text { diarrhea can be seen in COVID- } \\
\text { 19 infection (although rare). }\end{array}$ \\
\hline
\end{tabular}

Although respiratory signs and symptoms are most pronounced in COVID-19 infection, a typical malarial disease complicated with Acute Respiratory Distress Syndrome (ARDS) is nearly undifferentiable from severe COVID-19 infection.

In most African countries, community health workers (CHWs) are the frontline workers dealing with malaria, diagnosing cases with rapid diagnostic tests and treating simple cases. The current lack of 
widely validated antigen tests for COVID-19 with comparable sensitivity and specificity to RT-PCR tests hinder the ability of CHWs to accurately differentiate malaria from COVID-19 infection.

It is very likely that unrecognized COVID-19 disease transmitters will lead to a much wider virus spread, especially by those patients for whom a concurrent malarial disease is easily confirmed using the widely available rapid tests.

The picture of COVID-19 in Africa is confused by other endemic diseases with similar presentation, causing major challenges in the management of multiple public health threats. There is a growing need to reinforce the ability of fragile health systems to discriminate between multiple common causes. Without improved access to simple diagnostic tests there is possibility of patients being diagnosed and treated for one infection, only to die of another.

\section{Declarations}

\section{Consent:}

The consent to share this case report for both educational and COVID-19 strategic response purposes was obtained from the patient's next of kin.

\section{Competing interests:}

The authors declare no competing interests.

\section{References}

1. Michaud C. M. (2009). Global Burden of Infectious Diseases. Encyclopedia of Microbiology, 444454. https://doi.org/10.1016/B978-012373944-5.00185-1

2. World Malaria Report 2019. Accessed via the link: https://www.who.int/publications/i/item/worldmalaria-report-2019

3. Malaria's impact worldwide - CDC 2018

4. Malaria I WHO I Regional Office for Africa, 2017

5. Snow RW, Omumbo JA 2006. In: Jamison DT, Feachem RG, Makgoba MW, et al., editors. Disease and Mortality in Sub-Saharan Africa. $2^{\text {nd }}$ Washington (DC): The International bank for Reconstruction and Development/ The World Bank; 2006. Chapter 14.

6. S. President's Malaria Initiative Rwanda Malaria Operational Plan FY 2020. Retrieved from www.pmi.gov; Link: https://www.pmi.gov/docs/default-source/default-document-library/malariaoperational-plans/fy20/fy-2020-rwanda-malaria-operational-plan.pdf?sfvrsn=6

7. Africa CDC - Outbreak Brief 49: COVID-19 Pandemic - 22 December 2020. Accessed via the link: Outbreak Brief 49: Coronavirus Disease 2019 (COVID-19) Pandemic - Africa CDC 
8. Waidi Folorunso Sule et al. Real-time RT-PCR for COVID-19 diagnosis: challenges and prospects. Pan African Medical Journal. 2020;35(2):121. [doi: 11604/pamj.supp.2020.35.2.24258]

9. Kobia, F., \& Gitaka, J. (2020). COVID-19: Are Africa's diagnostic challenges blunting response effectiveness?. AAS open research, 3, 4. https://doi.org/10.12688/aasopenres.13061.1

10. Ellie Sherrard-Smith et al. The potential public health consequences of COVID-19 on malaria in Africa. Nature Medicine I Vol. 26 I September 2020 I 1411-1416 